with markedly increased frequency at the epoch of the equinoxes even at solar minimum.

The 'great storm' which next followed was, with a high degree of probability, directly associated with one or more solar flares within this sunspot region that had shown intense activity two months earlier. The magnetic storm began on September 21 with a marked 'sudden commencement' at $17 \mathrm{~h}$. $13 \mathrm{~m}$. U.T., but activity did not become conspicuous until $04 \mathrm{~h}$. $25 \mathrm{~m}$. on September 22. The most intense period was still later, between 10h. and 22h. Between 14h. and 15h., the movements of the traces were so rapid that ranges of $200 \gamma$ in $H$ in one minute of time were frequent. The storm ended rather uncertainly about 8 h. on September 23. The extreme ranges at Abinger (kindly communicated by the Astronomer Royal) were: $2^{\circ} 16^{\prime}$ in declination; $925 \gamma$ in horizontal force, and $450 \gamma$ in vertical force.

A complete but short-lived radio fade-out beginning at $11 \mathrm{~h} .05 \mathrm{~m}$. on September 21 was reported to Greenwich by Cable and Wireless Ltd., and during this fade-out a solar flare (not of great magnitude) was partially observed at Greenwich. But the statistical average time-interval between the beginning of a great magnetic storm and its antécedent intense solar flare is $21 \frac{1}{2}$ hours. This interval from the 'sudden commencement' at $17 \mathrm{~h}$. $13 \mathrm{~m}$. on September 21 would place the probable flare during the Greenwich night hours. Solar observations in $H \alpha$ from America, Australia and India are required to pursue further the connexion between this storm and a specifie solar outburst within the sunspot area.

\section{Experimental Stress Analysis Group}

A meeting was held at University College, London, on September 6, with the provost of the College, Dr. D. R. Pye in the chair and some sixty persons from academig, government and industrial research establishmen/s present to discuss the formation of a societ concerning itself with photo-elasticity. It was Aecided to extend the scope to other techniques of experimental stress analysis, and to form an informal group the object of which will be the interchange of knowledge and experience among its members. Some of the research workers had suggested that the group should be part of the Institute of Physics rather than form a new society. The secretary of the Institute of Physics, who was present by invitation, stated that the Institute was always prepared to give sympathetic consideration to requests from informal groups interested in applied physics for a little assistance in the inaugural period, and that this could be accepted without prejudice to the ultimate decision. It was therefore agreed to leave the constitution open for the present, and in the meantime to make a formal request to the Institute for temporary assistance.

Colonel H. T. Jessop (University College, London) was elected chairman of the Group, and Mr. E. K. Frankl (Engineering Department, University of Cambridge), honorary secretary. The following were elected to the Committee: Mr. W. A. P. Fisher (R.A.E., Farnborough), Mr. R. G. Manley (Vickers Armstrong, Ltd., Newcastle-on-Tyne), Mr. C. W. Newberry (L.M.S. Railway, Research Dept., Derby), Dr. S. C. Redshaw (Boulton Paul Aireraft Co., Wolverhampton), Mr. D. G. Sopwith (Engineering Div., National Physical Laboratory, Teddington), Dr. J. Ward (Huddersfield Technical College). The Committee was instructed to: (1) widen the circle of membership by getting in touch with research workers in all fields of experimental stress analysis; (2) make arrangements for a meeting within twelve months at which papers shall be read and the future constitution of the Group shall be decided ; (3) prepare and circulate bulletins of information which may be of interest to members. Any research workers or others who are interested in experimental stress analysis are invited to communicate with the honorary secretary of the Group.

\section{Dissemination of Scientific Information}

Among the papers presented at the Royal Society Empire Scientife Conference last July, a group dealing with dissemination of scientific information ampng entific workers do not appear to have been nfojed in the scientific and technical Press, althougd they indicate possibilities recently discussed in Aleve columns (see Nature, 157, 745; 1946). Prof. J. D. Bernal's contribution, "The Form and Distribution of Scientific Papers", briefly summarizes ideas he expressed at the Conference last year of the Association of Special Libraries and Information Bureaux, while Dr. L. M. Lampitt's paper, "An Abstracting Service", discussing the difficulty of reconciling both the informative and indicative abstract. nevertheless concludes that a central abstracting science service should be developed which should issue both types of abstract. On the council or board of this body would be representatives of all the major publishing societies and institutions. Both types of abstract should be highly sectionalized and the scheme should be financed jointly by the State, industry and the scientific worker. Dr. Lampitt's proposals thus go some way towards meeting the ideas of Prof. Bernal; Miss Ditmas' paper on "Special Libraries" also touches on the question of abstracting, but it is mainly concerned with the library system and with bibliographical services. Ideas presented in Mrs. Lucia Moholy's paper, "A Central Office of Documentary Reproduction", have already been discussed in Nature $(157,38 ; 1946)$, while the largest paper in this symposium, a review of information services by Prof. R. S. Hutton, supplements the other four contributions, examining the fundamental requirements of the collection and distribution of scientific and technical information, the growing difficulties which face such services, and indicating some proposals which have been made for improvement. Neither Prof. Hutton nor Miss Ditmas refers to the earlier report of the British Commonwealth Science Committee (cf. Nature, 152, 29; 1943), which contained a strong recommendation in favour of co-operation in abstracting services.

\section{British Medical Students' Journal}

"For the fir st time," says the editor of the first issue of th hurnal, "British medical students from all over th country are to produce a journal." The first $\mathrm{Nor}$ for this journal was drawn up by A. Malone of th fondon Hospital and D. Whittingham of Dewham, and the editorial board of three men and offeroman propose to publish in the future technical articles and news, "complemented wherever possible by art and literature of a high standard". Resisting attempts to impose upon them a partisan approach to many problems, the editorial board have wisely decided to be guided only by the wishes of the majority. They will fight for international co-operation and have, for this reason, devoted the whole of this first issue to an account of the new International Students' Federation and of the re-birth of the Czech 